\title{
The joint contributions of environmental filtering and spatial processes to macroinvertebrate metacommunity dynamics in the alpine stream environment of Baima Snow Mountain, Southwest China
}

\author{
Muhammad Farooq ${ }^{1}$, Xianfu Li ${ }^{2}$, Zhengfei $\mathrm{Li}^{3}$, Ronglong Yang ${ }^{2}$, Zhen $\mathrm{Tian}^{2}, \mathrm{Lu}_{\mathrm{Tan}}{ }^{3}$, \\ Davide Fornacca ${ }^{1}$, Yanpeng $\mathrm{Li}^{4}$, Nima $\mathrm{Cili}^{5}$, Zhongyong Ciren ${ }^{5}$, Shuoran $\mathrm{Liu}^{2}$, and Wen \\ $\mathrm{Xiao}^{4}$ \\ ${ }^{1}$ of Eastern-Himalaya Biodiversity Research, Dali University \\ ${ }^{2}$ Institute of Eastern-Himalaya Biodiversity Research, Dali University \\ ${ }^{3}$ Institute of Hydrobiology Chinese Academy of Sciences \\ ${ }^{4}$ Institute of Eastern-Himalaya Biodiversity Research \\ ${ }^{5}$ Deqin Administration Bureau, Baima Snow Mountain National Nature Reserve
}

November 8, 2021

\begin{abstract}
As a rapidly growing field of community ecology, the study of meta-communities provides an effective framework to unravel community assembly mechanisms by focusing on the relative contributions of environmental screening and spatial processes. While macroinvertebrates have been extensively investigated in many river ecosystems, meta-community ecology perspectives in high mountain stream networks are very limited. In this study, we assessed the role of ecological determinants and temporal dynamics in the macroinvertebrate meta-community assembly of an alpine stream situated in a dry-hot valley of Baima Snow Mountain, Northwest Yunnan. Our results show significant differences in the macroinvertebrate community composition across time periods. Spatial structuring and environmental filtering jointly drive the configuration of macroinvertebrate metacommunity, with relative contributions to the variance in community composition varying over time. Redundancy Analysis (RDA) and variation partitioning indicate that environmental variables are the most important predictors of community organization in most scenarios, whereas spatial determinants also play a significant role. Moreover, the explanatory power, identity, and the relative significance of ecological indicators change over time. Particularly, in the years 2018 and 2019, stronger environmental filtering was found shaping community assembly, suggesting that deterministic mechanisms predominated in driving community dynamics in such a specific environment of the stream. However, spatial factors had a stronger predictive power on meta-community structures in 2017, implying conspicuous dispersal mechanisms which may be owing to increased connectivity amongst locations. Thereby, we inferred that the stream macroinvertebrate metacommunity composition can be regulated by the interaction of both spatial processes and environmental filtering, with relative contributions varying over time. Based on these findings, we suggest that community ecology studies in aquatic systems should be designed beyond single snapshot investigations.
\end{abstract}

\section{INTRODUCTION}

Understanding the fundamental processes that drive Spatio-temporal changes in biological communities is one of the most pressing topics in community ecology. As an area, community ecology is concerned to explain the patterns of distribution, abundance, and archetype species interactions with each other (Leibold et al., 2004). Community ecologists proposed two key processes in order to describe the mechanisms that 
drive ecological communities (Tonkin et al., 2016). The deterministic, niche-based processes presume that species co-existence is based on ecological niche differentiation (Keddy, 1992). In this scenario, species that share identical functional characteristics should inhabit similar environments (Carvalho et al., 2020). Apart from this, stochastic processes presume that there is no ecological differentiation among species, and spatial characteristics are considered essential in constructing community assembly (Hubbell, 2004). Metacommunity ecology is one of the most intensively growing fields of community ecology, which provides an effective framework for studying community assembly mechanisms by integrating numerous ecological events, such as dispersal-linked and niche-based processes (Chase et al., 2020). This points to the fact that local communities are driven not only by local-scale environmental variables but also by regional-scale spatial factors (Mathew A Leibold \& Chase, 2017).

As reported by earlier works, environmental and spatial structuring both lead to change in an ecological community, yet their relative role varies depending on ecosystem types (Logue et al., 2011), seasonal changes (Chen et al., 2019), focal organisms' dispersal ability (Gray \& Arnott, 2011; Wang et al., 2020), and regional connectivity (Jamoneau et al., 2018). Although the community assembly mechanisms have mostly been measured up across various spatial scales, only a few studies have focused on how these mechanisms change temporally (Westveer et al., 2018). In general, due to the time lag in species colonization, spatial processes are highly significant during the early stages of community formation, while environmental processes take place in the later phases (Helsen et al., 2013). The above conclusions indicated that biological communities are not at equipoise, but are on the short-term course of advancing it, and are crucial to a comprehensive understanding of the processes that determine community organization over extended timescales (Chang \& HilleRisLambers, 2016), from years to decades (Alexander et al., 2012; Helsen et al., 2013). Besides, most previous studies based on snapshot sampling design, which may misrepresent the relative contribution of particular community-building processes, because they surmised that the mechanism regulating community variation remains constant over time ( $\mathrm{Li}$ et al., 2020). Consequently, separating the temporal changes of these core processes will present more specific knowledge to better understand the community assembly mechanisms.

Streams are very dynamic ecosystems on this planet, with considerable regional and temporal variation (Beche et al., 2006), and this variation is driven by both environmental and spatial components (Jiang et al., 2017). Thus, we selected a stream, notably in the dry-hot valley in order to quantify its specific environmental condition and macroinvertebrate communities. The macroinvertebrates were chosen as research organisms because they are useful indicators of stream integrity since they are affected by the stream's physicochemical and biological characteristics, as well as being relatively easy to sample and identify. Moreover, the prevailing environmental heterogeneity in a study area is an important element that affects the meta-community assembly (Bini et al., 2014). In particular, the relevance of environmental filtering is likely to vary among locations with varying degrees of environmental variability (M. A. Leibold et al., 2004). The role of environmental filtering on community structure is supposed to be greater within locations with higher environmental variability, although empirical support for this hypothesis is limited, particularly in stream ecosystems (Heino et al., 2015). The mechanisms of community assembly have been investigated in rivers and lowland streams ecosystem, but little is known about high mountain streams.

We collected macroinvertebrates and local environmental drivers from a stream, located in the unique environment of the Baima Snow Mountain (BSM). In the present study, we aimed to concentrate on stream benthic macroinvertebrates to better comprehend the community assembly mechanisms and the temporal changes of the mechanisms involved. Based on preceding knowledge of meta-community ecology in mountain freshwater bodies, we anticipated that both spatial structuring and environmental filtering induce variation in macroinvertebrate community composition, although their relative contributions would change over time (Chen et al., 2019; Csercsa et al., 2019). Particularly, we predicted that in such a specific environment of dry hot valley, assembly of macroinvertebrate communities would be primarily driven by environmental filtering, because strong stressors can compose a stringent environmental filter to select specific organisms (Chase, 2007). We also projected that increased bio-diversity and stronger environmental filtring determine community assembly across periods because more habitat variability would offer more niches for macroinvertebrates 
(Sarremejane et al., 2017), in such dry hot regions of BSM.

\subsection{MATERIALS AND METHODS}

\subsection{Study area}

The study region is located in the Baima Snow Mountain (BSM) Nature Reserve (Figure 1), Southwest China $\left(27^{\circ} 24-28^{\circ} 36^{\prime} \mathrm{N}, 98 \mathrm{deg} 57^{\prime}-99 \mathrm{deg} 25^{\prime} \mathrm{E}\right)$, which is the core part of the Hengduan Mountains, at heights extending from 2040 to 5429 meters. The Hengduan Mountains are one of the biodiversity hotspots in the world, located in a biogeographic transition zone between the Paleo-arctic and Oriental regions. This region has a cold temperate climate influenced by the monsoon, resulting in distinct wet (May to October) and dry (November to April) seasons, with rising altitude, the weather regime shifts, resulting in deep valleys dry and hot, whereas mountain summits are typically cold. The combination of altitude and climate gradient enables a reasonably distinct differentiation of main mountain forest types by altitudinal belts. Additional details on the environment of the research area can be found in the work of Wen et al. (2014) and Wu et al. (2013).

\subsection{Environmental factors and Benthic Macroinvertebrates}

The sampling was carried out over three years periods (2017, 2018, and 2019). We sampled a total of 9 sites following the altitudinal gradient along the Sharong (SR) stream, located in the specific environment of BSM. The stream was shallow and long, with cobble, pebbles and, gravel beds, with a maximum width of 2 meters. Along the altitudinal gradient, different types of vegetation were present within the region surrounding the sampling sites. The sites further upstream were generally devoid of human activities, as located farther away from human settlements, whereas agricultural practices occurred around the middle area of the sampling sites., however, the downstream sites $(\mathrm{n}=3)$ were located in the specific environment of the dry-hot valley. A Surber net $(30$ X $30 \mathrm{~cm}, 500 \mu \mathrm{m}$, mesh size) was used to collect macroinvertebrate samples, and the items that remained on the net were carefully picked and stored in 75 percent ethanol for preservation purposes. Five replicates were randomly taken at each sampling point to cover multiple habitat types. The five replicates of macroinvertebrate specimen samples were then pooled to illustrate the community composition of each site. All the sampled specimens were then classified to the lowest taxonomic level (usually to genus and possibly to morphospecies level) except Orthocladiiae, Tanypodinae, Chironominae, Chironomidae, Dolichopodidae, and Elmidae were classified to family level using relevant taxonomic reference books (Dudgeon, 1999; Morse et al., 1994), literature in the lab (Jacobus, 2008; Jacobus, 2009; Shi \& Tong, 2015), and online assets (https://www.freshwaterecology.info). We assessed the effect of the subsequent set of local environmental factors on benthic communities, including conductivity (COND- $\mathrm{S} / \mathrm{cm})$, total dissolved solids (TDS-mg/L), dissolved oxygen (DO-mg/L), salinity (Sal), water temperature (WT- ${ }^{\circ} \mathrm{C}$ ), oxidation-reduction potential $(\mathrm{ORP}-\mathrm{mV})$, and hydrogen ion concentration $(\mathrm{pH})$ were quantified using a portable multi-parameter probe (YSI Professional plus, U.S.A) in the field. The geographical coordinates and altitude (ALT-m) of the sampling points were determined using a GPS device (Garmin eTrex20, China). These factors were measured at each sampling site after macroinvertebrate sampling.

\subsection{Spatial factors}

In a multi-species metacommunity, dispersal is a complex and convoluted ecological process that is hard to measure. As a result, ecologists are compelled to exploit proxies, such as spatial eigenfunction analysis, to indirectly determine an organism's dispersal process (Heino et al., 2017). In order to simulate the spatial linkages of community composition between sampling points at different levels, the principal coordinates of neighbor matrices (PCNM) method were employed to generate spatial components based on geographic coordinates between sampling sites for additional analysis. The PCNM method is frequently used in biological communities for simulating spatial structures (Pierre Legendre \& Legendre, 2012). Further, we retained the PCNM vectors with positive eigenvalues as dispersal-related components (spatial factors) (Gilbert \& Bennett, 2010), based on overland distance. Since they indicate a possible positive auto-correlation between spatial sites at multiple scales (Dray \& Legendre, 2008). The first PCNM vectors represent large-scale spatial linkages between locations, whereas the latter spatial vectors demonstrate smaller-scale differences 
between sites. Finally, we retrieved 6 PCNM vectors and these vectors were then used as explanatory factors in multivariate ordination. The PCNM vectors (spatial factors) were retrieved using the function pcnm in the $\mathrm{R}$ vegan package (P Legendre et al., 2013).

\subsection{Data Analysis}

All biological and environmental data from the different periods were pooled and analyzed with various descriptive and inferential statistics. Prior to statistical analysis, environmental factors were z-score standardized and the community matrix was transformed by $\log (\mathrm{x}+1)$ to improve normality. The nonparametric Kruskal-Wallis test was used to examine potential environmental differences across periods. In addition, we conducted Principal Coordinates Analysis (PCoA) to portray differences in community structure across periods with the Bray-Curtis Index as a distance measurement. The nonparametric multivariate statistical test (PERMANOVA; adonis) and pairwise (adonis) tests were employed to further corroborate the divergence in community composition. The Rank Abundance Curve (RAC) was plotted to illustrate the most dominant macroinvertebrate taxa for each period. Redundancy analysis (RDA) and the associated variation partitioning algorithm were employed to illuminate the relative roles of local environmental and spatial determinants in shaping macroinvertebrate communities. RDA ordination was carried out to assess the connections between benthic macroinvertebrate community composition and local environmental and spatial determinants, accordingly. The environmental variables were z-scored standardized, whereas the community data was Hellinger transformed as needed by the RDA model prior analysis. Further, a forward selection approach was used to screen both environmental and spatial elements to identify a set of significant components in the R package adespatial (Dray et al., 2017). To show the relative contributions of environmental variables and spatial determinants to change in community composition, the variation partitioning analysis was employed to derive the pure environmental variables, pure spatial factors, their shared fractions, and unexplained fractions in the $\mathrm{R}$ vegan package using the function 'varpart'. Adjusted $\mathrm{R}^{2}$ values were used to present the results since they represent unbiased measures of explicated variance (Peres-Neto et al., 2006). Moreover, the PERMDISP analysis was used to evaluate if there were discrepancies in biological and environmental heterogeneity across periods. We selected to utilize Euclidean distance on z-scored standardized environmental factors and Bray-Curtis distance on community abundance data. All statistical analyses were carried out in the R-statistic environment (R Development Core Team, 2018), while the map was created by using QGIS 3.8 .

\subsection{RESULTS}

\subsection{Environmental conditions}

In general, the first three principal components explained $91.53 \%$ of the variation, the local environmental factors such as conductivity (Cond), water temperature (WT), dissolved oxygen (DO), hydrogen ion concentration (pH), Salinity (Sal), and total dissolved solids (TDS) were positively correlated on the first principle component, while altitude (ALT) and oxidation-reduction potential (ORP) were negatively correlated. The first axis (PC1) explained $49.98 \%$ variation (Figure 2), which was primarily related to the factors ALT, Cond, Sal, and TDS. The second axis (PC2) explained $31.21 \%$ of the variation was mainly associated with WT, DO, and pH. Overall, the PCA biplot showed WT, DO, and altitude gradients along with the sites. The key indicators that contributed greatly to the total variations in the first six principal components were ALT, DO, WT, ORP, and pH.

Moreover, except for $\mathrm{pH}$, DO, and ORP, the remaining environmental components were not significantly different across periods such as WT, ALT, TDS, COND, and Sal (Appendix 1). Particularly, the 2017 period had higher values of WT and $\mathrm{pH}$, while the DO concentration was found to be higher in the 2019 sampling time, and the remaining factors had nearly equal values across the periods. PERMANOVA implied that mean environmental conditions differed significantly between time $(\mathrm{F}=7.144, \mathrm{P}=0.001)$. However, PERMDISP analysis indicated no significant effect in the variance of the environmental heterogeneity across periods $(\mathrm{F}=$ 0.010; $\mathrm{P}>0.05$ ). In the context of the variation of the environmental heterogeneity, the 2019 period (mean Euclidean distance: 3.05), was quite flexible than both 2017 (average Euclidean distance: 2.94), and 2018 
periods (average Euclidean distance: 2.93)

\subsection{Macroinvertebrates composition}

A total of 17,823 individuals of macroinvertebrates were collected during the entire sampling period, representing 73 taxa, corresponding to 3 phyla, 6 classes, 12 orders, 47 families, and 61 genera (Appendix 2). Freshwater insects accounted for 86.05\% (65 taxa), followed by Clitellata (2 taxa, 13.28\%), Malacostraca (1 taxon, 0.39\%), Rhabditophora and Arachnida (both 1 taxon 0.10\%), and Entognatha (1 taxon, 0.04\%). Macroinvertebrate species with maximum existence frequency were Baetiella marginata , Limnodrilussp., Baetis sp1., Prosimulium sp., and Amphinemurasp1.

As a whole, 53, 52, and 59 macroinvertebrates taxa were sampled across three years periods $(2017,2018$, and 2019). In terms of relative abundance, the top three dominant species in the period 2017 wereBaetis sp1. (23.32\%), Rhithrogena sp1. (19.55\%), andB. marginata (12.93\%), whereas B. marginata (21.45\%), Limnodrilus sp. (17.06\%), and Orthocladiiae (10.88\%) were dominant in the period 2018. Similarly, B. marginata (24.15\%),Limnodrilus sp. (14.39\%), and Prosimulium sp. (12.16\%) were dominant in the period 2019 (Appendix 2). Moreover, Principal Coordinates Analysis (PCoA) visualized notable differences in community composition between the three periods. The first axis of PCoA explained $24.51 \%$ of the variation in macroinvertebrate communities composition, whereas the second axis accounted for $15.89 \%$ of the variation (Figure 3), in total $40.40 \%$. In addition, the variance of the first six PCoA axes explained $74.43 \%$ of the variation in community composition. These results of principal coordinates analysis are further supported by the ANOSIM test $(\mathrm{P}=0.001, \mathrm{R} 2=0.6)$.

Further the PERMANOVA and pairwise.adonis tests supported the findings of principal coordinates analysis that the macroinvertebrate community composition differed significantly across time, 2017-2018 ( $\mathrm{F}=3.200$, $\mathrm{P}=0.001), 2017-2019(\mathrm{~F}=7.163, \mathrm{P}=0.002)$, and 2018-2019 $(\mathrm{F}=4.014, \mathrm{P}=0.002)$ respectively. However, PERMDISP found no significant variations in macroinvertebrate community heterogeneity (or beta diversity) among periods $(\mathrm{F}=1.706, \mathrm{P}=0.2)$. The findings demonstrated a location effect, not a dispersion effect on the community composition of macroinvertebrates (e.g., PERMANOVA output) The Rank Abundance Curves (RAC) showed that B. marginata (Sp45) were among the most present taxa in both 2018 and 2019 sampling time, while Baetis sp1. was the most prevalent in 2017 (Figure 4).

Other characteristic taxa were Rhithrogena sp1. (Sp54), B. marginata, and Limnodrilus sp. (Sp65) for the period 2017; and in the period 2018, Limnodrilus sp., Orthocladiiae (Sp31), and Baetis sp1. (Sp42), while Limnodrilus sp.,Prosimulium sp. (Sp39), and Amphinemura sp1. (Sp8) for the period 2019.

Only richness differed significantly across time, with higher species richness in the period 2019 (Figure 5). In contrast, Simpson index, Shannon index, and Evenness were not significantly different across time, and slightly higher diversity values were observed in the 2019 sampling period, followed by 2017.

\subsection{Important local environmental variables and spatial components}

The forward selection approach indicated that oxidation-reduction potential (ORP), water temperature (WT), and conductivity (COND) were significantly related with the macroinvertebrate communities in the 2017 sampling period, while total dissolved solids (TDS), hydrogen ion concentration (pH), salinity (Sal), and dissolved oxygen (DO) displayed to be imperative in determining macroinvertebrate communities in the period 2018. Similarly, in the 2019 sampling period, oxidation-reduction potential (ORP), water temperature (WT), and hydrogen ion concentration $(\mathrm{pH})$ were found to be significantly structuring macroinvertebrate communities (Figure 6, Table 1).

Based on the forward selection approach, Spatial factors analysis revealed that PCNM1, PCNM2, and PCNM3 were maintained in the period 2017, while PCNM1, and PCNM2, were retained in the period 2018. Similarly, in the 2019 sampling period, PCNM1 and PCNM2 were selected (Figure 6, Table 1).

3.4 Relative roles of environmental and spatial components 
As evidenced by the outputs of the variation partitioning approach, environmental variables and spatial determinants all played potentially key roles in organizing macroinvertebrate communities relying on both unique (individual) and joint fractions. Overall, the variation partitioning approach showed that pure environmental factors, spatial determinants, and their shared effects combined elucidated $65 \%$ of the community change in the period $2017,53 \%$ in 2018 , and $24 \%$ of community variation in the period 2019 , respectively (Figure 7).

Throughout the three periods, The relative strength of local environmental variables and spatial determinants were considerably different. The environmental factors elucidated more variation than spatial components. Particularly, only in the period 2017, spatial factors explained more of the variations (29\%) compared to environmental variables (11\%). On the other hand, in the period 2018 environmental factors accounted for $22 \%$ of the community variation than spatial components (19\%). Similarly, in the period 2019, environmental factors accounted for $11 \%$ of the community changes compared to spatial factors (1\%). Conversely, the shared fractions that are described collectively by both environmental and spatial determinants are also considered for significant variations, with $25 \%$ of community variations explained in 2017 , and $12 \%$ in both the 2018 and 2019 periods, correspondingly.

\section{DISCUSSION}

Our findings present the first concise picture of macroinvertebrate community structure and temporal dynamics in the Sharong stream of Baima Snow Mountain. There was a marked shift of macroinvertebrates community structure across time. Also, significant variation in macroinvertebrate communities was explained by both environmental and spatial determinants, showing that dispersal-linked and niche-based mechanisms were both crucial for macroinvertebrate's community assembly. Such finding corroborated meta-community ecology's key ideas (Leibold et al., 2004), and also a vast number of empirical research conducted in both aquatic (Heino et al., 2012; Kärnä et al., 2015) and terrestrial environments (Reinhardt et al., 2005; Tsang \& Bonebrake, 2017). Mainly, our study revealed that the explanatory rate and identity of spatial and environmental components change over time. This result highlighted the necessity of studying assembly mechanisms over time (Vidal et al., 2014), as well as implied that the results from snapshot sampling design may not provide a complete picture (Vidal et al., 2014; Zhang et al., 2019). The spatially structured environmental factors also contributed significantly to the macroinvertebrate's meta-community. The shared effects of environmental and spatial elements, on the other hand, are difficult to interpret. Usually, in studies of aquatic meta-communities, such shared effects are rather typical (Vilmi et al., 2016).

Earlier studies on the comparative role of spatial and environmental processes in determining aquatic organism structure have given inconsistent findings. For instance, Heino \& MYKRÄ (2008), in their study found no spatial location effects on stream macroinvertebrates assemblages, given that these assemblages were not highly dispersal constrained over the study drainage system. On the other hand, Vanschoenwinkel et al. (Vanschoenwinkel et al., 2007) indicated that local environmental components were more important than spatial determinants in predicting invertebrate community composition and that both these factors acted nearly independently. Thus, in most scenarios, an RDA-based variation partitioning approach in our study revealed that environmental filtering predominated in governing macroinvertebrate meta-communities, corroborating the notion that species sorting is usually the primary mechanism shaping benthic macroinvertebrate communities. These findings are consistent with other studies conducted in various water bodies (Castillo-Escrivà et al., 2017; Li et al., 2020; Vanschoenwinkel et al., 2007, 2010).

In our study, spatial determinants also accounted for a significant proportion of variance in stream macroinvertebrate communities, implying that dispersal constraint and mass effects may influence meta-community structure (Cottenie, 2005; Heino, 2013), should be considered in routine monitoring and evaluation efforts. Since our study was conducted in a mountainous region, we conclude that spatial signals in community structures are produced by dispersal constraints. Besides, based on the forward selection approach spatial components with larger eigenvalues, for example, PCNM1 and PCNM2 were chosen, implying that broadscale spatial processes were essential in shaping the stream macroinvertebrates meta-community. In the present study, the macroinvertebrate community composition was significantly different across periods and 
most macroinvertebrates in the Sharong stream are generally small-sized and short-lived taxa, their lifehistory strategies, and phenology are highly associated with their reproduction, emergence, recruitment, and overwintering in time (Raitif et al., 2018). The apparent temporal trends of abundance and occurrence were determined for the majority of macroinvertebrates, containing the four utmost abundant taxa in each period (Figure 3 and Appendix 2). Thus, temporal dynamics in species abundance and identity, as well as the ecological circumstances may be related to the shifts in the comparative contribution of spatial structuring and environmental screening (filtering) temporally.

Despite the fact that the importance of spatial components and environmental factors changed over time, we did find that the explanatory rate and identity of both environmental factors and spatial determinants altered across periods. Thereby, our findings corroborate the prediction that community assembly processes exhibit temporal changes in the study region, emphasizing the need of investigating community assembly processes from a temporal viewpoint (Li et al., 2020).

Our findings also revealed that both in the periods 2018 and 2019, stronger environmental filtering was found shaping community assembly, suggesting that deterministic mechanisms predominated in driving community dynamics in such a specific environment of the dry hot valley. This finding was reasonable since the roles of environmental filtering are anticipated to be robust with growing environmental stiffness throughout the period with low water current (flow) (Sarremejane et al., 2017). In our study, several environmental factors such as water temperature (WT), total dissolved solids (TDS), dissolved oxygen (DO), conductivity (COND) oxidation-reduction potential (ORP) hydrogen ion concentration $(\mathrm{pH})$, salinity (Sal), and significantly elucidated the changes in macroinvertebrate communities, thereby these factors act as environmental filters that select for the most adapted taxa in the regional species pool. In addition, the role of spatial factors was fairly lower than that of environmental factors and was temporally variable. However, we also observed a strong predictive potential of spatial determinants over meta-community structures only in the period 2017. According to Datry et al. (2016), the relative contribution of dispersal-linked processes on biotic communities was likely affected by rapid recolonization after a flood event. One factor that cannot be overlooked is that spatial signal could be amplified by the enormous fly of fully adult insects. Conversely, in our study, we primarily examined stream macroinvertebrates larvae, which indicate we may have neglected dispersal patterns of fully adult insects, limiting the generalizability of our findings. Therefore, future research should take into account varied dispersal strategies of aquatic larvae and adults in such particular habitats of dry hot valleys. This study could have implications for biomonitoring in the context of a meta-community (Cid et al., 2020) when utilizing macroinvertebrate taxa as ecological indicators. For instance, biological monitoring programs may be less efficient in identifying degraded and impaired locations in the study region, owing to the substantial migration of individuals of these taxa from immaculate sites to adjacent impacted sites (Heino et al., 2017). We assume that the most important environmental factors were assessed and comprised in this study; however, it remains to be evaluated that the pure spatial effects ascertained can be associated with the effect of certain unquantified environmental factors or demonstrate actual spatial constraints in functional assemblage composition. Besides, more comprehensive statistical methodology and experimental examination on a spatial-temporal scale are needed to better understand the important mechanisms driving macroinvertebrates' meta-community in alpine streams.

\section{CONCLUSION}

Our research contributed to the meta-community studies in the high-mountain freshwater system by combining different ecological processes driving variation in community structure. The results showed that both spatial structuring and environmental filtering jointly drive the structure of macroinvertebrate metacommunity, although their relative contributions to variance in community composition varied in time. In general, our findings revealed that environmental variables were the most important predictors of community organization in most scenarios, whereas spatial determinants also played a significant role. Moreover, we found that the identity, explanatory rate, and relative significance of assembly processes changed over time. Thus, we assert that a single snapshot sampling design is inadequate for assessing these meta-community dynamics-influencing ecological processes. The findings also render implications for bioassessment programs, 
such programs, for example, maybe extremely biased if we utilize organisms groups as bioindicators that imply a robust connection to dispersal-related mechanisms. These findings highlight the need of incorporating dispersal strategies in meta-community studies in terms of understanding the relative roles of environmental and spatial dynamics in time.

\section{FUNDING STATEMENT}

This research was funded by the National Natural Science Foundation Program of P.R. China [31760126, U1602262, 31960255], supported by the Second Tibetan Plateau Scientific Expedition and Research Program (STEP), Grant No. SQ2019QZKK2002, the provincial innovation team of biodiversity conservation and utility of the three parallel rivers region from Dali University and the "Key Laboratory of Yunnan State Education Department on Erhai Lake Basin Protection and the Sustainable Development Research".

\section{CONFLICTS OF INTEREST}

The authors declare no conflict of interest.

\section{AUTHOR CONTRIBUTIONS}

Muhammad Farooq: Conceptualization (equal); formal analysis (equal); writing-original draft (equal); writing-review and editing (equal); visualization (equal); Validation (equal). Xianfu Li: Field sampling (equal); methodology (equal); visualization (equal); Validation (equal). Zhengfei Li: Conceptualization (equal); writing-review and editing (equal); visualization (equal); Validation (equal). Ronglong Yang: Field sampling (equal); methodology (equal). Zhen Tian: Field sampling (equal); methodology (equal). Lu Tan: Methodology (equal); visualization (equal); Validation (equal). Davide Fornacca : Writing-review and editing (equal); visualization (equal); Validation (equal). Yanpeng Li: Field sampling (equal); visualization (equal); Validation (equal). Nima Cili: Field sampling (equal); methodology (equal). Zhongyong Ciren: Field sampling (equal); methodology (equal). Shuoran Liu: Conceptualization (equal); methodology (equal); writing-review and editing (equal); supervision (equal); Validation (equal). Wen Xiao: Conceptualization (equal); Validation (equal); Validation (equal); visualization (equal); funding acquisition (equal).

\section{DATA AVAILABILITY STATEMENT}

Macroinvertebrates and explanatory data would be deposited in the Dryad Digital Repository, XXX.

\section{REFERENCES}

Alexander, H. M., Foster, B. L., Ballantyne IV, F., Collins, C. D., Antonovics, J., \& Holt, R. D. (2012). Metapopulations and metacommunities: combining spatial and temporal perspectives in plant ecology. Journal of Ecology , 100 (1), 88-103.

Beche, L. A., Mcelravy, E. P., \& Resh, V. H. (2006). Long-term seasonal variation in the biological traits of benthic-macroinvertebrates in two Mediterranean-climate streams in California, USA. Freshwater Biology , $51(1), 56-75$.

Bini, L. M., Landeiro, V. L., Padial, A. A., Siqueira, T., \& Heino, J. (2014). Nutrient enrichment is related to two facets of beta diversity for stream invertebrates across the United States. Ecology ,95 (6), 1569-1578.

Cai, Y., Zhang, Y., Hu, Z., Deng, J., Qin, B., Yin, H., Wang, X., Gong, Z., \& Heino, J. (2019). Metacommunity ecology meets bioassessment: Assessing spatio-temporal variation in multiple facets of macroinvertebrate diversity in human-influenced large lakes.Ecological Indicators , 103 , 713-721.

Carvalho, J. C., Malumbres-Olarte, J., Arnedo, M. A., Crespo, L. C., Domenech, M., \& Cardoso, P. (2020). Taxonomic divergence and functional convergence in Iberian spider forest communities: Insights from beta diversity partitioning. Journal of Biogeography , 47 (1), 288-300. https://doi.org/10.1111/jbi.13722 
Castillo-Escriva, A., Valls, L., Rochera, C., Camacho, A., \& Mesquita-Joanes, F. (2017). Metacommunity dynamics of Ostracoda in temporary lakes: Overall strong niche effects except at the onset of the flooding period. Limnologica, 62 , 104-110.

Chang, C., \& HilleRisLambers, J. (2016). Integrating succession and community assembly perspectives. F1000Research , 5 .

Chase, J. M. (2007). Drought mediates the importance of stochastic community assembly. Proceedings of the National Academy of Sciences , 104 (44), 17430-17434.

Chase, J. M., Jeliazkov, A., Ladouceur, E., \& Viana, D. S. (2020). Biodiversity conservation through the lens of metacommunity ecology.Annals of the New York Academy of Sciences , 1469 (1), 86-104.

Chen, W., Ren, K., Isabwe, A., Chen, H., Liu, M., \& Yang, J. (2019). Stochastic processes shape microeukaryotic community assembly in a subtropical river across wet and dry seasons. Microbiome, 7 (1), $1-16$.

Cid, N., Bonada, N., Heino, J., Canedo-Arguelles, M., Crabot, J., Sarremejane, R., Soininen, J., Stubbington, R., \& Datry, T. (2020). A metacommunity approach to improve biological assessments in highly dynamic freshwater ecosystems. BioScience, 70 (5), 427-438.

Cottenie, K. (2005). Integrating environmental and spatial processes in ecological community dynamics. Ecology Letters , 8 (11), 1175-1182.

Csercsa, A., Krasznai-K, E. A., Varbiro, G., Szivak, I., Toth, M., Arva, D., Bodis, E., Deak, C., Mauchart, P., \& Mora, A. (2019). Seasonal changes in relative contribution of environmental control and spatial structuring on different dispersal groups of stream macroinvertebrates.Hydrobiologia , 828 (1), 101-115.

Datry, T., Bonada, N., \& Heino, J. (2016). Towards understanding the organisation of metacommunities in highly dynamic ecological systems. Oikos , 125 (2), 149-159.

Dray, S., Blanchet, G., Borcard, D., Guenard, G., Jombart, T., Larocque, G., Legendre, P., Madi, N., \& Wagner, H. H. (2017). adespatial: Multivariate multiscale spatial analysis. R Package Version 0.0-9 .

Dray, S., \& Legendre, P. (2008). Testing the species traits-environment relationships: the fourth-corner problem revisited.Ecology , 89 (12), 3400-3412.

Dudgeon, D. (1999). Tropical Asian streams: zoobenthos, ecology and conservation (Vol. 1). Hong Kong University Press.

Gilbert, B., \& Bennett, J. R. (2010). Partitioning variation in ecological communities: do the numbers add up? Journal of Applied Ecology , 47 (5), 1071-1082.

Gray, D. K., \& Arnott, S. E. (2011). Does dispersal limitation impact the recovery of zooplankton communities damaged by a regional stressor? Ecological Applications , 21 (4), 1241-1256.

Heino, J. (2013). The importance of metacommunity ecology for environmental assessment research in the freshwater realm.Biological Reviews , 88 (1), 166-178.

Heino, J., Alahuhta, J., Ala-Hulkko, T., Antikainen, H., Bini, L. M., Bonada, N., Datry, T., Eros, T., Hjort, J., Kotavaara, O., Melo, A. S., \& Soininen, J. (2017). Integrating dispersal proxies in ecological and environmental research in the freshwater realm. Environmental Reviews , 25 (3), 334-349. https://doi.org/10.1139/er-2016-0110

Heino, J., Gronroos, M., Soininen, J., Virtanen, R., \& Muotka, T. (2012). Context dependency and metacommunity structuring in boreal headwater streams. Oikos , 121 (4), 537-544.

Heino, J., Melo, A. S., Bini, L. M., Altermatt, F., Al-Shami, S. A., Angeler, D. G., Bonada, N., Brand, C., Callisto, M., \& Cottenie, K. (2015). A comparative analysis reveals weak relationships between ecological 
factors and beta diversity of stream insect metacommunities at two spatial levels. Ecology and Evolution, 5 (6), 1235-1248.

Heino, J., \& MYKRA, H. (2008). Control of stream insect assemblages: roles of spatial configuration and local environmental factors.Ecological Entomology , 33 (5), 614-622.

Helsen, K., Hermy, M., \& Honnay, O. (2013). Spatial isolation slows down directional plant functional group assembly in restored semi-natural grasslands. Journal of Applied Ecology ,50 (2), 404-413.

Hubbell, S. P. (2004). The unified neutral theory of biodiversity and biogeography: reply. Ecology , 85 (11), $3175-3178$.

Jacobus, L M. (2008). Revision of Ephemerellidae Genera (Ephemeroptera) . 185 , 185-274.

Jacobus, Luke M. (2009). Two new species of Asian Serratella Edmunds . 58 , 52-58.

Jamoneau, A., Passy, S. I., Soininen, J., Leboucher, T., \& Tison-Rosebery, J. (2018). Beta diversity of diatom species and ecological guilds: Response to environmental and spatial mechanisms along the stream watercourse. Freshwater Biology , 63 (1), 62-73.

Jiang, X., Xiong, J., \& Xie, Z. (2017). Longitudinal and seasonal patterns of macroinvertebrate communities in a large undammed river system in Southwest China. Quaternary International , 440 , 1-12.

Karna, O., Gronroos, M., Antikainen, H., Hjort, J., Ilmonen, J., Paasivirta, L., \& Heino, J. (2015). Inferring the effects of potential dispersal routes on the metacommunity structure of stream insects: as the crow flies, as the fish swims or as the fox runs? Journal of Animal Ecology , 84 (5), 1342-1353.

Keddy, P. A. (1992). Assembly and response rules: two goals for predictive community ecology. Journal of Vegetation Science ,3 (2), 157-164. https://doi.org/10.2307/3235676

Legendre, P, Borcard, D., Blanchet, F. G., \& Dray, S. (2013).PCNM: MEM spatial eigenfunction and principal coordinate analyses. $R$ package version 2.1-2/r109 .

Legendre, Pierre, \& Legendre, L. (2012). Numerical ecology . Elsevier.

Leibold, M. A., Holyoak, M., Mouquet, N., Amarasekare, P., Chase, J. M., Hoopes, M. F., Holt, R. D., Shurin, J. B., Law, R., Tilman, D., Loreau, M., \& Gonzalez, A. (2004). The metacommunity concept: A framework for multi-scale community ecology. Ecology Letters , 7 (7), 601-613. https://doi.org/10.1111/j.14610248.2004.00608.x

Leibold, Mathew A, \& Chase, J. M. (2017). Metacommunity ecology, volume 59 . Princeton University Press.

Li, Z., Xing, Y., Liu, Z., Chen, X., Jiang, X., Xie, Z., \& Heino, J. (2020). Seasonal changes in metacommunity assembly mechanisms of benthic macroinvertebrates in a subtropical river basin. Science of the Total Environment, 729 , 139046.

Logue, J. B., Mouquet, N., Peter, H., Hillebrand, H., \& Group, M. W. (2011). Empirical approaches to metacommunities: a review and comparison with theory. Trends in Ecology 86 Evolution , 26 (9), 482-491.

Morse, J. C., Yang, L., \& Tian, L. (1994). Aquatic insects of China useful for monitoring water quality (Issue 13). Hohai University Press.

Peres-Neto, P. R., Legendre, P., Dray, S., \& Borcard, D. (2006). Variation partitioning of species data matrices: estimation and comparison of fractions. Ecology , 87 (10), 2614-2625.

Raitif, J., Plantegenest, M., Agator, O., Piscart, C., \& Roussel, J.-M. (2018). Seasonal and spatial variations of stream insect emergence in an intensive agricultural landscape. Science of the Total Environment , 644, 594-601. 
Reinhardt, K., Kohler, G., Maas, S., \& Detzel, P. (2005). Low dispersal ability and habitat specificity promote extinctions in rare but not in widespread species: the Orthoptera of Germany. Ecography ,28 (5), $593-602$.

Sarremejane, R., Canedo-Arguelles, M., Prat, N., Mykra, H., Muotka, T., \& Bonada, N. (2017). Do metacommunities vary through time? Intermittent rivers as model systems. Journal of Biogeography , 44 (12), $2752-2763$.

Shi, W., \& Tong, X. (2015). Taxonomic notes on the genus Baetiella Ueno from China, with the descriptions of three new species (Ephemeroptera: Baetidae) . 4012 (3), 553-569.

Team, R. C. (2018). R Foundation for Statistical Computing, Vienna, available at: www. R-Project. Org .

Tonkin, J. D., Stoll, S., Jahnig, S. C., \& Haase, P. (2016). Elements of metacommunity structure of river and riparian assemblages: communities, taxonomic groups and deconstructed trait groups.Ecological Complexity , $25,35-43$.

Tsang, T. P. N., \& Bonebrake, T. C. (2017). Contrasting roles of environmental and spatial processes for common and rare urban butterfly species compositions. Landscape Ecology , 32 (1), 47-57.

Vanschoenwinkel, B., De Vries, C., Seaman, M., \& Brendonck, L. (2007). The role of metacommunity processes in shaping invertebrate rock pool communities along a dispersal gradient. Oikos , 116 (8), 12551266.

Vanschoenwinkel, B., Waterkeyn, A., Jocque, M., Boven, L., Seaman, M., \& Brendonck, L. (2010). Species sorting in space and time - the impact of disturbance regime on community assembly in a temporary pool metacommunity. Journal of the North American Benthological Society , 29 (4), 1267-1278.

Vidal, T., Santos, J. I., Marques, C. R., Pereira, J. L., Claro, M. T., Pereira, R., Castro, B. B., Soares, A., \& Goncalves, F. (2014). Resilience of the macroinvertebrate community of a small mountain river (Mau River, Portugal) subject to multiple stresses. Marine and Freshwater Research , 65 (7), 633-644.

Vilmi, A., Karjalainen, S. M., Hellsten, S., \& Heino, J. (2016). Bioassessment in a metacommunity context: are diatom communities structured solely by species sorting? Ecological Indicators ,62 , 86-94.

Wang, J., Legendre, P., Soininen, J., Yeh, C., Graham, E., Stegen, J., Casamayor, E. O., Zhou, J., Shen, J., \& Pan, F. (2020). Temperature drives local contributions to beta diversity in mountain streams: Stochastic and deterministic processes. Global Ecology and Biogeography , 29 (3), 420-432.

Wen, Z., Wu, Y., Du, Y., Xia, L., Ge, D., Yang, Q., \& Chen, L. (2014). Seasonal change of species diversity patterns of non-volant small mammals along three subtropical elevational gradients.Biotropica , 46 (4), $479-488$.

Westveer, J. J., van der Geest, H. G., van Loon, E. E., \& Verdonschot, P. F. M. (2018). Connectivity and seasonality cause rapid taxonomic and functional trait succession within an invertebrate community after stream restoration. PloS One, 13 (5), e0197182.

Wu, Y., Yang, Q., Wen, Z., Xia, L., Zhang, Q., \& Zhou, H. (2013). What drives the species richness patterns of non-volant small mammals along a subtropical elevational gradient? Ecography , 36 (2), 185-196.

Zhang, Y., Peng, C., Huang, S., Wang, J., Xiong, X., \& Li, D. (2019). The relative role of spatial and environmental processes on seasonal variations of phytoplankton beta diversity along different anthropogenic disturbances of subtropical rivers in China. Environmental Science and Pollution Research , 26 (2), 14221434 .

Table 1 Results of the forward selection method in the Redundancy Analysis for three years time periods

$$
2017 \text { F-value P-value }
$$

2017 F-value P-value

2017 F-value P-value

2018 F-va

$\operatorname{ALT}(\mathrm{m})$ 


\begin{tabular}{|c|c|c|c|c|}
\hline & 2017 F-value P-value & 2017 F-value $\mathrm{P}$-value & 2017 F-value $\mathrm{P}$-value & 2018 F-va \\
\hline $\begin{array}{l}\text { COND ( } \mu \mathrm{s} / \mathrm{cm}) \\
\text { Sal }(\mathrm{ppt}) \\
\text { TDS }(\mathrm{mg} / \mathrm{L})\end{array}$ & 2.224 & & 0.04 & 0.04 \\
\hline $\begin{array}{l}\mathrm{WT}\left({ }^{\circ} \mathrm{C}\right) \\
\mathrm{DO}(\mathrm{mg} / \mathrm{L}) \\
\mathrm{pH}\end{array}$ & 3.584 & & 0.05 & 0.05 \\
\hline ORP (mV) PCNM1 PCNM2 PCNM3 & 4.1288 .4893 .9573 .273 & & $0.01<0.010 .010 .02$ & $0.01<0.0$ \\
\hline
\end{tabular}

Appendix 1 General statistics of local environmental variables and results of the Kruskal-Wallis (nonparametric) test for three periods. "*" and "***" denote significant differences at $\mathrm{P}<0.05$ and $\mathrm{P}<0.001$, respectively, whereas "ns" denotes non-significant differences.

\begin{tabular}{|c|c|c|c|c|c|}
\hline & 2017 Max Min Mean & 2017 Max Min Mean & 2017 Max Min Mean & 2018 Max Min Mean & $2018 \mathrm{Ma}$ \\
\hline$\overline{\operatorname{ALT}(m)^{\mathrm{ns}}}$ & 3769 & 2417 & 3041 & 3041 & 3800 \\
\hline $\operatorname{COND}(\mu \mathrm{s} / \mathrm{cm})^{\mathrm{ns}}$ & 286.4 & 172 & 246.54 & 246.54 & 259 \\
\hline Sal (ppt) ${ }^{\text {ns }}$ & 0.19 & 0.12 & 0.16 & 0.16 & 0.18 \\
\hline $\operatorname{TDS}(\mathrm{mg} / \mathrm{L})^{\mathrm{ns}}$ & 250.9 & 167.7 & 217.89 & 217.89 & 239.85 \\
\hline $\mathrm{WT}\left({ }^{\circ} \mathrm{C}\right)^{\mathrm{ns}}$ & 13.7 & 7.5 & 10.88 & 10.88 & 13 \\
\hline $\mathrm{DO}(\mathrm{mg} / \mathrm{L}) * * *$ & 7.87 & 6.94 & 7.4 & 7.4 & 8.12 \\
\hline $\mathrm{pH} * * *$ & 8.96 & 8.62 & 8.86 & 8.86 & 8.56 \\
\hline $\mathrm{ORP}(\mathrm{mV}) * * *$ & 138.1 & 80.6 & 110.96 & 110.96 & 236.9 \\
\hline
\end{tabular}

Appendix 2 Identified taxa of macroinvertebrates found in the Sharong stream of Baima Snow Mountain. Abund refers to abundance and Prop refers to proportions of each taxon in different years. The top 3 dominant species have shown in bold in the table for each year.

\begin{tabular}{|c|c|c|c|c|c|c|c|c|}
\hline Classes & Families & Orders & Genus/Taxàd & $\begin{array}{l}2017 \\
\text { Abund }\end{array}$ & Prop & $\begin{array}{l}2018 \\
\text { Abund }\end{array}$ & Prop & $\begin{array}{l}2019 \\
\text { Abund }\end{array}$ \\
\hline ArthropodaInsecta & Perlidae & Plecoptera & $\begin{array}{l}\text { KamimuriaSp1 } \\
\text { sp. }\end{array}$ & 2 & 0.04 & 2 & 0.05 & 7 \\
\hline ArthropodaInsecta & Perlidae & Plecoptera & $\begin{array}{l}\text { Neoperla Sp2 } \\
\text { sp. }\end{array}$ & 1 & 0.02 & 0 & 0 & 0 \\
\hline ArthropodaInsecta & Perlodidae & Plecoptera & $\begin{array}{l}\text { ParacapniaSp3 } \\
\text { sp. }\end{array}$ & 57 & 1.36 & 12 & 0.34 & 57 \\
\hline ArthropodaInsecta & Perlodidae & Plecoptera & $\begin{array}{l}\text { Isoperla } \mathrm{Sp} 4 \\
\text { sp. }\end{array}$ & 25 & 0.59 & 4 & 0.11 & 13 \\
\hline ArthropodaInsecta & Peltoperlid & ARlecoptera & $\begin{array}{l}\text { CryptoterlaSp5 } \\
\text { sp. }\end{array}$ & 27 & 0.64 & 20 & 0.56 & 25 \\
\hline ArthropodaInsecta & Chloroperl & iłdecoptera & $\begin{array}{l}\text { Sweltsa } \quad \text { Sp6 } \\
\text { sp. }\end{array}$ & 12 & 0.28 & 0 & 0 & 67 \\
\hline ArthropodaInsecta & Capniidae & Plecoptera & $\begin{array}{l}\text { EucapnopsiSp7 } \\
\text { sp. }\end{array}$ & 113 & 2.70 & 260 & 7.40 & 364 \\
\hline ArthropodaInsecta & Nemourida & Alecoptera & $\begin{array}{l}\text { Amphinemwris } \\
\text { sp1. }\end{array}$ & 119 & 2.84 & 136 & 3.87 & 1050 \\
\hline ArthropodaInsecta & Nemourida & Alecoptera & $\begin{array}{l}\text { Amphinem } \\
\text { sp2. }\end{array}$ & 38 & 0.90 & 0 & 0 & 2 \\
\hline
\end{tabular}




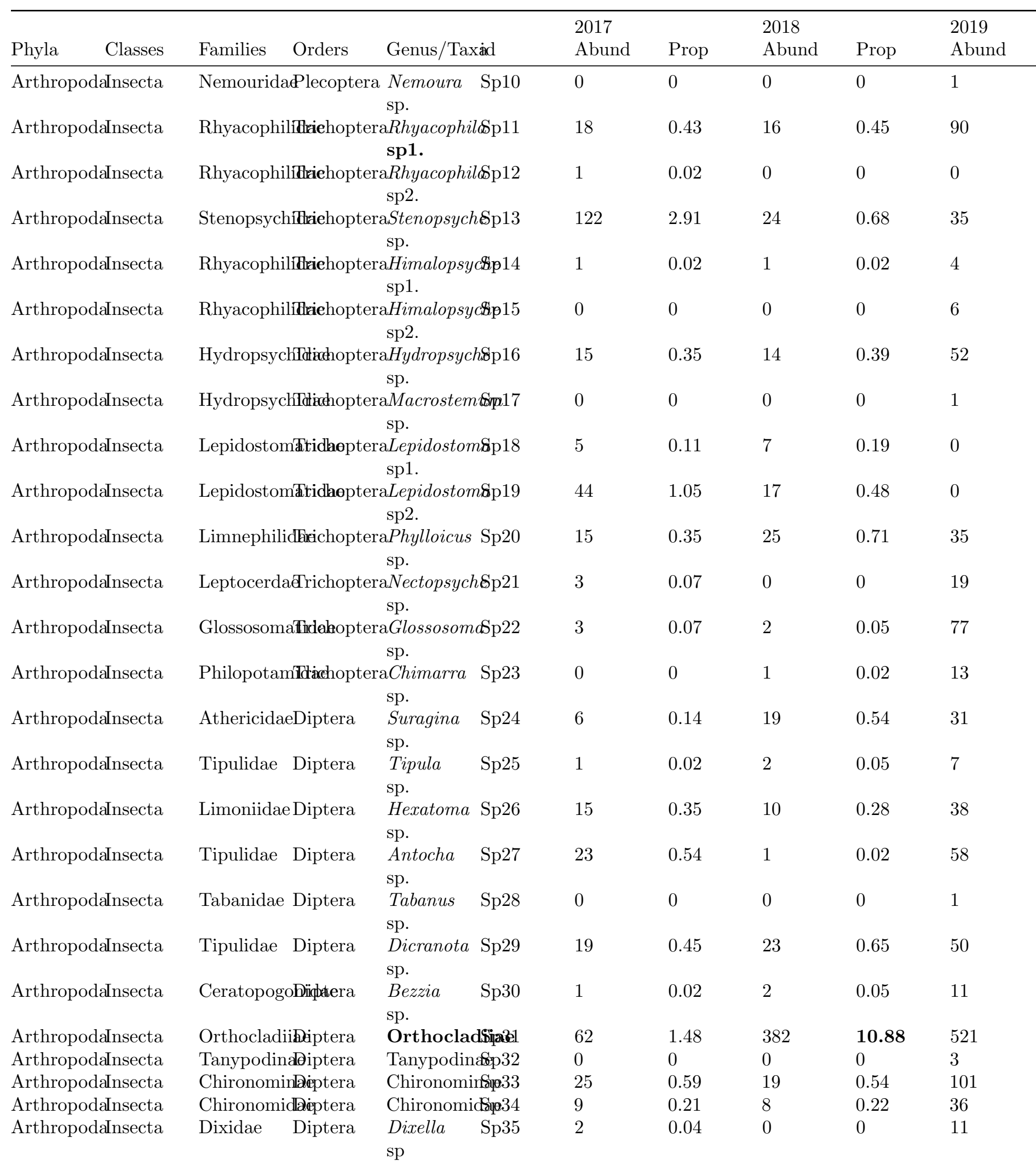




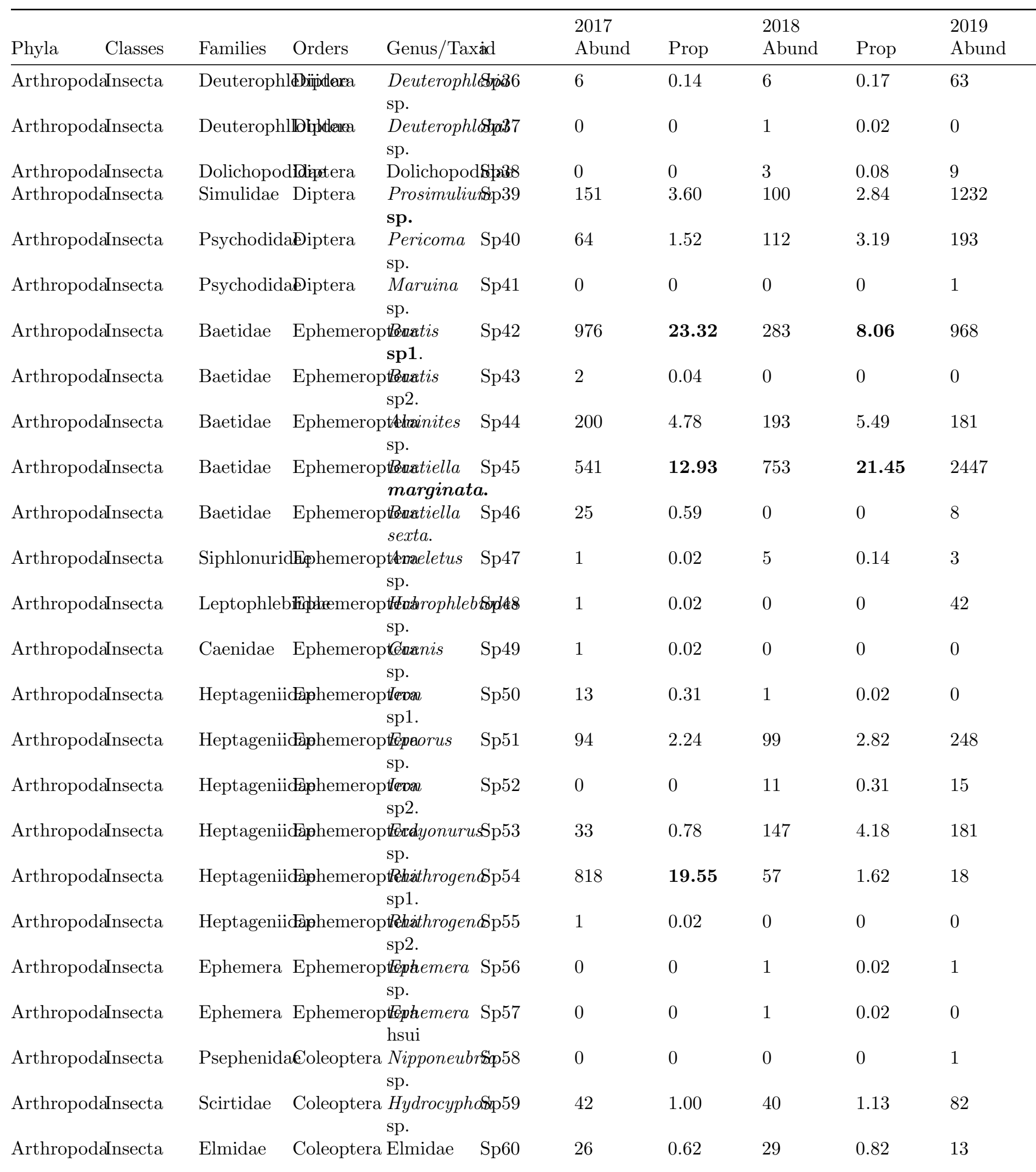




\begin{tabular}{|c|c|c|c|c|c|c|c|c|c|}
\hline Classes & Families & Orders & Genus/Tax & & $\begin{array}{l}2017 \\
\text { Abund }\end{array}$ & Prop & $\begin{array}{l}2018 \\
\text { Abund }\end{array}$ & Prop & $\begin{array}{l}2019 \\
\text { Abund }\end{array}$ \\
\hline ArthropodaInsecta & Elmidae & Coleoptera & $\begin{array}{l}\text { Stenelmis } \\
\text { sp. }\end{array}$ & Sp61 & 3 & 0.07 & 25 & 0.71 & 93 \\
\hline ArthropodaInsecta & Elmidae & Coleoptera & $\begin{array}{l}\text { Oulimnius } \\
\text { sp. }\end{array}$ & Sp62 & 75 & 1.79 & 1 & 0.02 & 18 \\
\hline ArthropodaInsecta & Dytiscidae & Coleoptera & $\begin{array}{l}\text { Hydaticus } \\
\text { sp. }\end{array}$ & Sp63 & 0 & 0 & 1 & 0.02 & 0 \\
\hline ArthropodaInsecta & Hydrophilic & däøleoptera & $\begin{array}{l}\text { Berosus } \\
\text { sp. }\end{array}$ & Sp64 & 0 & 0 & 1 & 0.02 & 0 \\
\hline Annelida Clitellata & Tubificidae & Tubificida & $\begin{array}{l}\text { Limnodrilu } \\
\text { sp. }\end{array}$ & L & 304 & 7.26 & 599 & 17.06 & 1458 \\
\hline PlatyhelminRhaळditoph & hroranariidae & eTricladida & $\begin{array}{l}\text { Planaria } \\
\text { sp. }\end{array}$ & Sp66 & 0 & 0 & 4 & 0.11 & 15 \\
\hline Annelida Clitellata & Glossiphon & iitdrangnchob & $\begin{array}{l}\text { dedpiolladella } \\
\text { sp. }\end{array}$ & Sp67 & 1 & 0.02 & 2 & 0.05 & 4 \\
\hline ArthropodaArachnida & Hydrachnic & dilarembidifo & $\begin{aligned} \text { mrmader } \\
\text { mites }\end{aligned}$ & Sp68 & 1 & 0.02 & 1 & 0.02 & 17 \\
\hline ArthropodaEntognatha & aPoduridae & Poduromor & $\begin{array}{l}\text { rpblodura } \\
\text { sp. }\end{array}$ & Sp69 & 0 & 0 & 4 & 0.11 & 4 \\
\hline ArthropodaMalacostrad & arammarid & aAmphipodi & $\begin{array}{l}\text { aGammarus } \\
\text { sp. }\end{array}$ & Sp70 & 21 & 0.50 & 23 & 0.65 & 27 \\
\hline ArthropodaInsecta & Osmylidae & Neuroptera & $\begin{array}{l}\text { a Osmylus } \\
\text { sp. }\end{array}$ & Sp71 & 0 & 0 & 0 & 0 & 1 \\
\hline
\end{tabular}

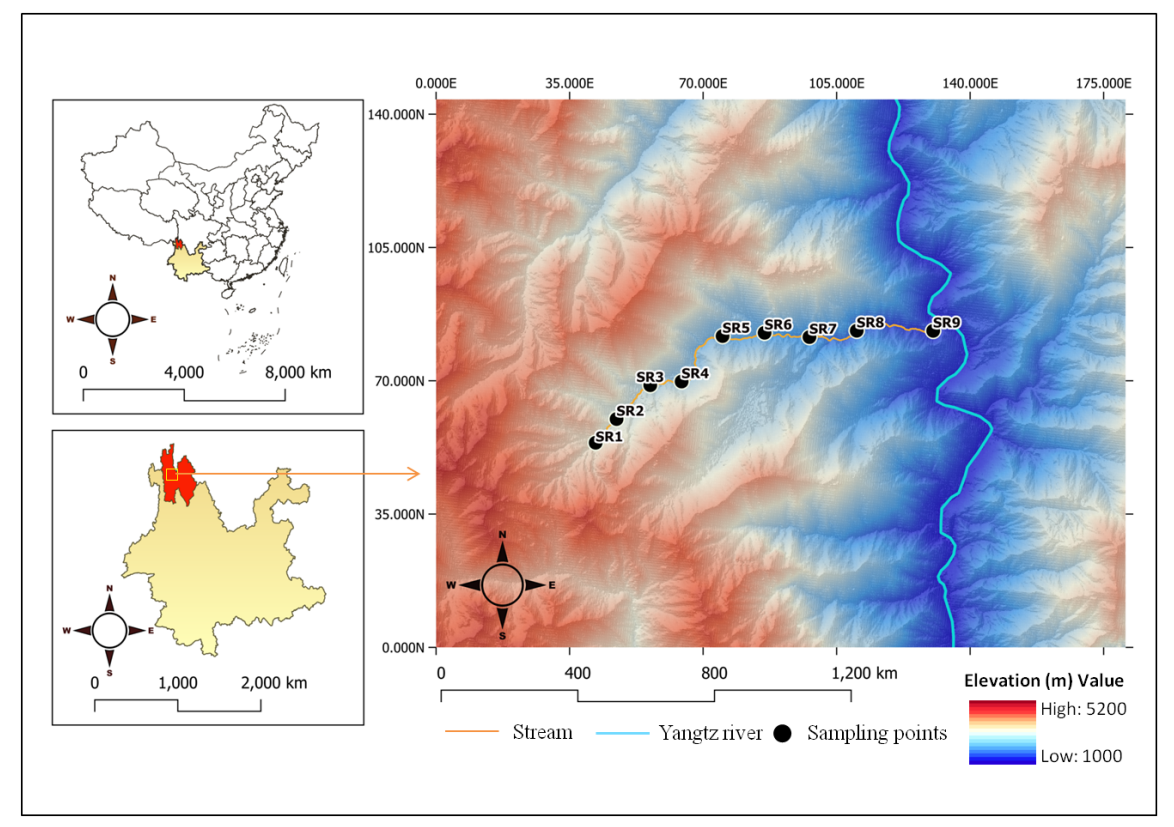



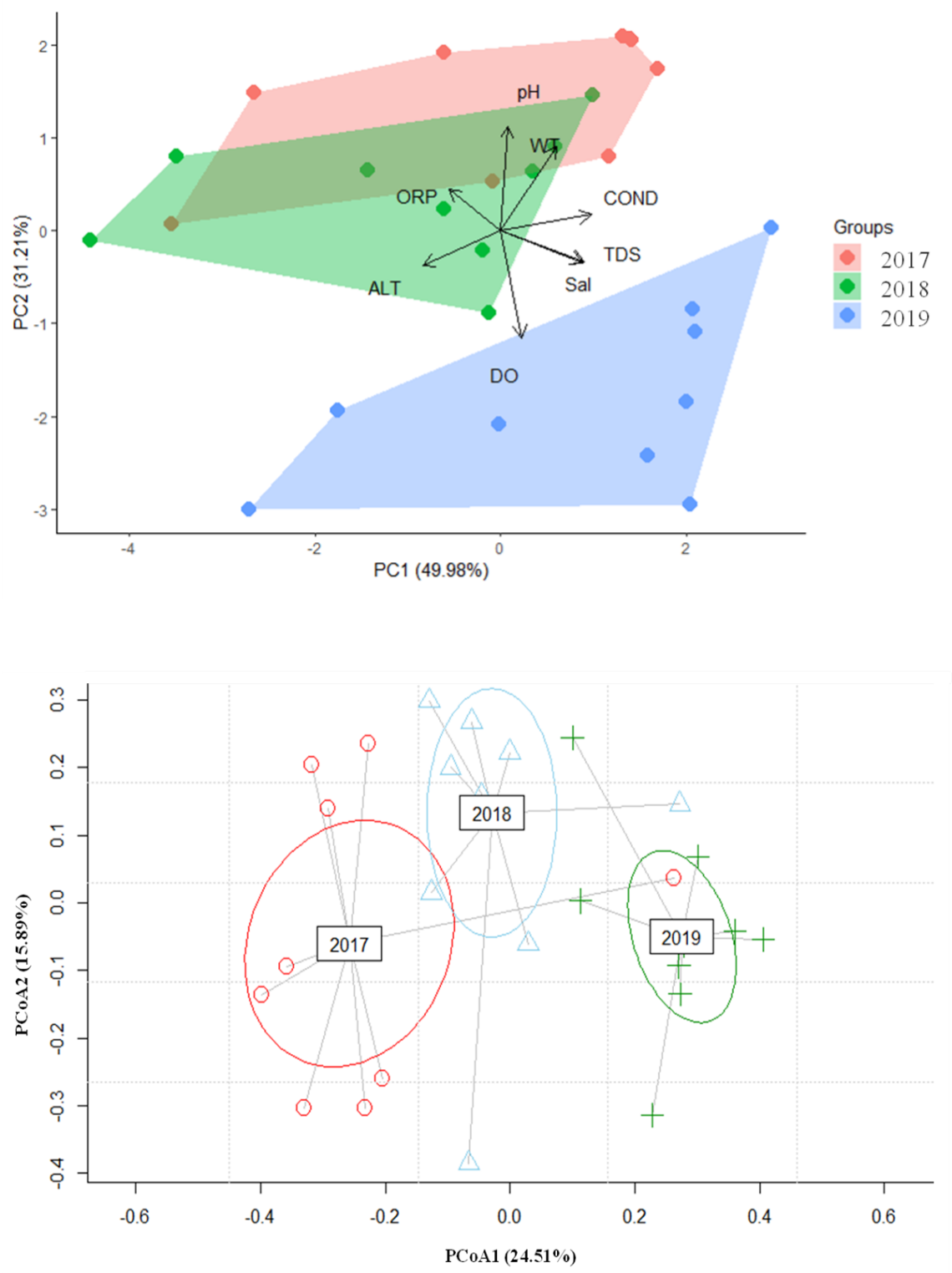

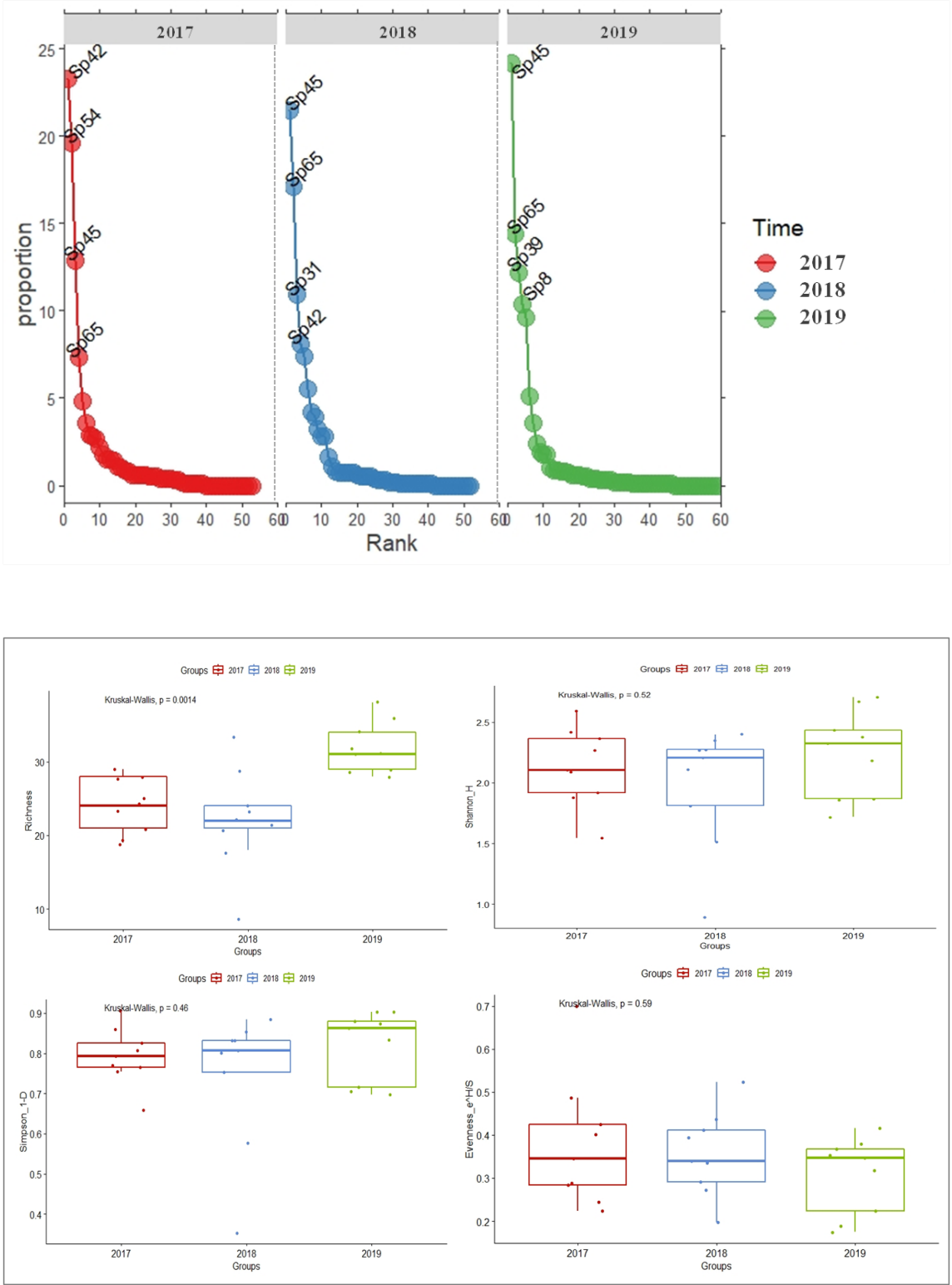

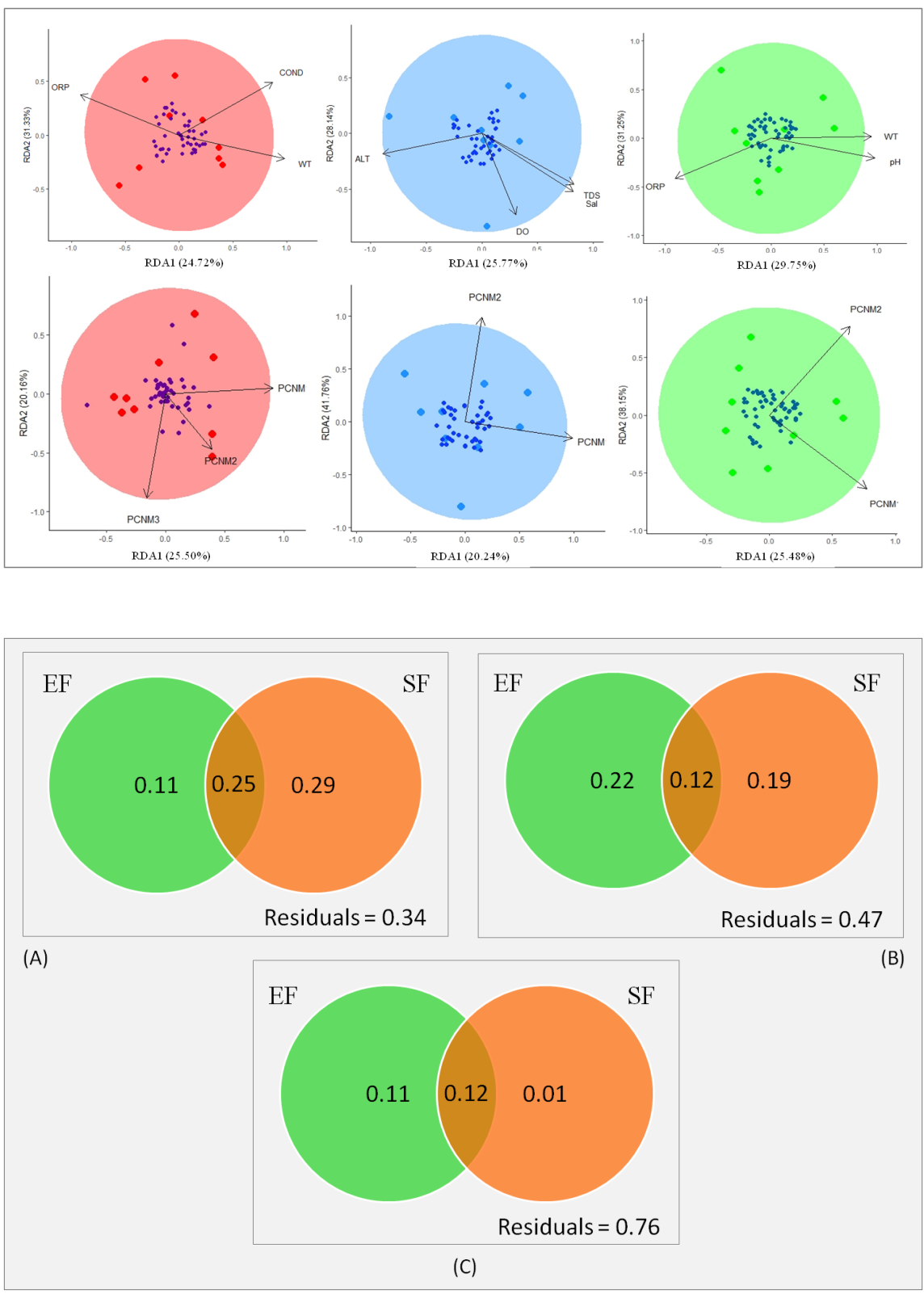